\title{
A Corpus-based Study on the Influence of Chinese Circular Thought Pattern and Collectivism on English Writing
}

\author{
Liwei Sun \\ School of Arts and Science, Jilin Agricultural Science and Technology College, Jilin 132101
}

Keywords: Corpus-based, Influence, Circular thought pattern, Collectivism, English Writing.

\begin{abstract}
This paper takes the analysis of the influence of the Chinese circular thought pattern and collectivism on English writing. CLEC ( Chinese learner English corpus) is used as the main source of data collection. It can be seen from the analysis that Chinese circular thought pattern and collectivism have a profound influence on English writing. A thorough understanding of the differences in thought patterns between Chinese and English will be necessary in the acquisition of English writing.
\end{abstract}

\section{Introduction}

The awareness of the different thought patterns between Chinese and the native English speakers has long been noticed by many scholars and researchers, yet most of their researches and works only lay emphasis on the distinction between the two thought patterns and the distinction between the two languages respectively. Even though some of the research works are aware of the influence of the Chinese thought patterns on the learning of English, yet due to the inadequacy of data, seldom of them could achieve a satisfying result. Herein, the paper is drafted with the intention to help English learners to be aware of the influence of Chinese circular thought pattern and collectivism on English writing with the assistance of CLEC (Chinese Learner English Corpus). The source of data collection is St3 and St4 which are the sub-corpora of CLEC. Meanwhile, Some data from the comparative corpora of the native English speakers such as BROWN and LOB are also collected for conducting the research. From the analysis, it can be concluded that as a result of the circular thought pattern and collectivism, Chinese English learners tend to use Chinese discourse patterns in their English writing.

\section{Circular Thought pattern VS Linear Thought pattern}

\section{Circular Thought pattern}

Kaplan(1966) uses the following diagrams to express several different thought patterns. They represent respectively the thought patterns of the people who speak Chinese, Korean, English, Latin, and Russian. Many experts believe that this is an exact picture of different cultural thought patterns; the other experts (Parl, 2004; Connor, 1996) think that these thought patterns mainly represent the characteristics of different cultural discourse structures. In any case, Robert Kaplan's idea has now been widely accepted by the linguists and has greatly influenced the practice of translation and discourse analysis.
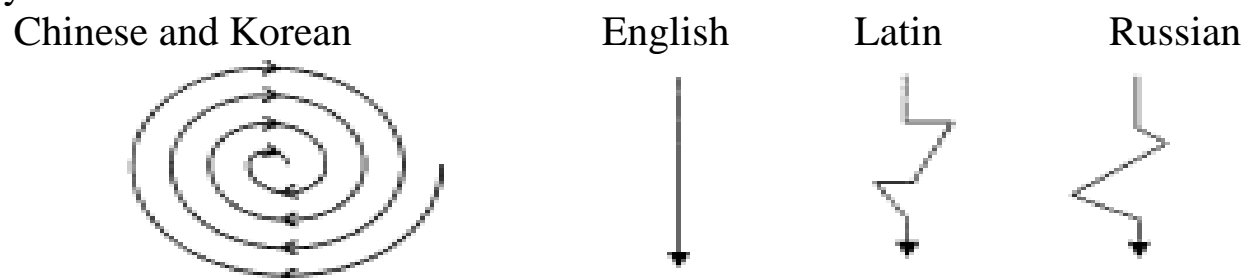

Fig 2.1 Diagram from Robert B. Kaplan, “Cultural Thought patterns in Intercultural Education,” language learning, 16, nos. 1 and 2: 15. 
According to Kaplan, Chinese thought pattern is circular or non-linear while the westerners including the native English speakers are apt to be linear. (Kaplan, 1966). Circular thought pattern goes from infinite to finite, from big to small and integrate independent parts into a whole. It is characterized by circumlocution, that is, not stating opinion directly or frankly but beating about the bush at first, using rhetorical devices such as metaphor, analogy to develop opinion, then going back to the topic at last; or intentionally referring to history, tradition or something else to conceal the theme.

This thought pattern is heavily influenced by traditional Chinese culture and society. There are a great many proverbs that can reflect the idea of Confucius such as: "Two heads are better than one" "Modesty helps one to go forward while pride results in failure". Influenced by the idea of "be polite and modest”, the Chinese tend to show politeness and modesty to others and do not manifest their criticism and dissatisfaction explicitly. As a result, their words and deeds are always evasive and obscure, their thinking is indirect. Besides, feudalism has existed in China for about 1000 years and its influence is also deep-rooted. Under the influence of feudal hierarchy, ordinary Chinese people must be discreet. Therefore, they dare not express their ideas or feelings directly but beat about the bush. When explaining issues, they do not come to the point directly, but drop a hint. Chinese scholars in ancient times often use the stereotyped writing, "eight-legged essay" is a typical example. The author usually puts forward the background information at the beginning, then expounds and elaborates it, later turns to a new topic and finally comes to a conclusion.

\section{Linear Thought pattern}

Kaplan (1966) claims that the basic feature of English writing is that it normally follows a straight line of development. The paragraph often begins with a statement of its central ideas. These subdivisions have the purpose of developing the topic sentence, preparing for the addition of other ideas in later paragraphs. According to Robert Kaplan (1966), linear thinking is also called deductive thinking and general-specific thinking. Like circular thought pattern, linear thought pattern is also closely associated with its traditional culture and philosophy. This type of thought pattern can be traced back to Aristotelian times. Aristotle starts formal logic, which exerts a far-reaching influence on occidental linear thinking. Aristotle puts forward two thought patterns: deduction and induction. However, he attaches more importance to deduction and regards deduction as a superior thought pattern. Since then, deduction becomes not only a means to form theoretical system for western scholars but a habitual thinking for westerners. In addition, Aristotle divides the discourse of a speech into four parts: beginning, question raising, analyzing and expounding, conclusion. Based on his theory, modern people divide an article into three parts: introduction, body and conclusion. An English composition especially a research paper usually begins directly with the topic and then argues about the different aspects respectively to the end. Therefore, the structure of the English discourse is like a triangle or the underground roots of a tree.

\section{Collectivism VS Individualism}

\section{Collectivism}

The collectivist thought pattern is recognized by Samovar and Richard E. Porter(1995), who maintain in their Communication Between Cultures that China is a typical nation that attaches great importance to collectivism. According to them, collectivism is characterized by a rigid social framework that distinguishes between in-groups and out-groups. People count on their in-group(relative, clans, organizations)to look after them, and in exchange for that they believe they owe absolute loyalty to the group. In collective societies such as China, people are born in extended families or clans that support and protect them for their loyalty. The Chinese have developed a very intensive agricultural economy with the help of a widespread government-fostered system of irrigation since ancient times. Thus it was possible for a large of group of population to subsist upon a comparatively small amount of land. Peasants are tied to the land on which they live and work from generation to generation. Except in times of war and famine, there is little mobility. In China, a "we" consciousness prevails: "identity is based on social system; individual is emotionally dependent on organizations and institutions. 


\section{Individualism}

Individualism holds that the individual is the primary unit of reality and the ultimate standard of value. It is characterized by individuals who are subordinate the goals of collectives to other personal goals. A key belief of people is that the smallest unit of survival is the individual. Individualism manifests itself in individual initiative, independence, individual expression, and privacy. From our literature to art and history, the message is the same: individual achievement, sovereignty, and freedom are the virtues most glorified. Our role models, be they the cowboys of the Old West or action heroes in today's movies, are all portrayed as independent agents who accomplish their goals with little or no assistance. The result of these and countless other messages is that most westerners believe that each person has his or her own separate identity, which should be recognized and reinforced.

In a culture that tends toward individualism, an "I" consciousness prevails: personal goals take precedence over group goals; competition is encouraged rather than cooperation; people tend not to be emotionally dependent on organizations and institutions and every individual has the right to his or her private property, thinking, and opinions. These culture stress individual initiative and achievement, and they value individual decision-making.

\section{The Influence of the Circular Thought Pattern and Collectivism on English writing}

The influence of the circular thought pattern can mainly be seen in the level of discourse. It is well known that Confucianism, Taoism, and Buddhism, which have great influence on Chinese society, all pursue intuition, that is, the power of understanding the meaning between lines. As a result of the emphasis on intuition, Chinese people are inclined to make judgments based on the events that occurred before, or precedent, in other words, Chinese believe that something happened with a precedent to refer to is more valid and trustworthy. Such thought is also reflected in Chinese language. For instance, people tend to use an indirect way to express their opinions or use an ambiguous statement. Furthermore, Chinese tradition emphasizes collective power and collectivism. It does not allow for much individual self-expression. The position, function and opinion of an individual have always been reduced. Such as, the English learners tend to apply more "We" as the subject of a sentence than the native English speakers do as can be seen from the data collected from CLEC and its comparative corpora:

Table 4.15 The Frequency of "We" in CLEC, BROWN and LOB

\begin{tabular}{|l|l|l|l|}
\hline Frequency & CLEC & BROWN & LOB \\
\hline $\mathrm{We}$ & 2706 & 2001 & 2001 \\
\hline
\end{tabular}

All these factors lead to the indirectness in Chinese though pattern. On the contrary, the ideas of Ancient Greek philosophers like Socrates, Plato and Aristotle have great influence upon the society of the native English speakers. They advocate logic and reasoning. In addition, individual's point of view is emphasized in the history of the whole western society. Such thought reflected in English language is people's attempt to express their opinions directly. English speakers are unlikely to spend much time in "small talk" or in setting up a background for the main point. They come to the point immediately. The English cultural preference is for clear and direct communication as evidence by many common English expressions, "say what you mean", "Don't beat around the bush", and "get to the point". In general, English contains linearity and directness in expression.

The most famous foreign scholar is Kaplan, who conducted a research into the rhetorical practices of students whose first languages was not English. After examining nearly seven hundred English essays written by non-native students, Kaplan(1966)published his paper in Language and Learning entitled "Cultural Thought Pattern in Intercultural Education" . The seven-hundred compositions were contrast with the normal, linear topic development expected by native readers of English. He pointed out, through research, that students from different cultural backgrounds tend to show different ways of putting forward their points of view. In general, Kaplan argued that Chinese as well as other "Oriental" writing is indirect. A subject is not discussed directly but is approached from a variety of indirectly related view. Such thought patterns of Chinese contribute to the 
preference for indirectness when it is concerned with the writing of the Chinese English learners. In CLEC, there are a large number of such examples. Here two samples of the original data are collected randomly from st3 and st4, the sub-corpora of CLEC to discuss such circular thought pattern.

Sample from st3: $<$ ST $3><$ Getting to Know the World Outside the Campus $><$ SCORE $11><$ ID 451626>With the development of modern society, it is necessary for college students to have a good grasp [wd3,1-2] of society. Modern society is complex and developing all the time. Because we always study on campus, we don't know how to adapt to society in the future, how to get on with others in the company. Society is different from campus. It has different atmosphere. When we graduate, it means that we come into a new working space which we know little about it. So we should know something about it. The approaches to know about society are various. For example, we can read newspapers, megines and watch TV to learn information about society . Also we can practice in society by our-self , we can participate in free service activities so that we can know how to do in the future. On campus, I'll do my best to study well. At the same time, I'll get to know as more as possible about the world outside the campus in order to work freely in the future.

Sample from st4: $<$ ST $4><$ TITLE Haste Makes Waste $><$ SCORE $7><$ ID 430916 $>$ When someone is filling a bottle with water, and he is impatient, so he makes it quickly but most of the water is dropped out of the bottle. Obviously he needs more time and becomes slower. Like this, we call, Haste makes waste. Then, why do haste makes waste. Firstly, I think, haste can makes people upset, and then influence his acts. Secondly, once people haste, he can not control his activeness well and does things in wrong ways. For instance, someone is haste to get train . The time is rather limited, so he is upset, he takes his suitcase hurried to the railway station. When he arrives at the station, he finds his ticket is forgotten in his home. Such examples are many. And in order to avoid it and make things good and quick, we should not haste and we ought to make calme.

As can be seen from these two writings, at the beginning of the writing, the students don't get to the point directly, but talking of some background information first, for example, in the sample of st3, in order to illustrate the topic of "Getting to Know the World outside the Campus" the author doesn't say directly about the necessity and ways of getting to know the world outside the campus, but talking in a round about way about the weak point of us and the disadvantage of staying in the campus. In the sample from st4, “Hast Makes Waste”, the author doesn't mention the topic statement directly but using an example to cite it. It is just in contrast with the writing style of the native English speakers who write in a direct way. English writing is characterized as begin with a topic statement, then developing the topic with related ideas supporting it, and at last making a conclusion of the whole essay. The following is the opinion of an American concerning the effect of climate on culture:

"Climate effects the culture of a country. Men must learn to live within the limitations of their environment, and climate is an important part of the physical environment. Life in a tropical country is less strenuous and more casual than it is in a temperate one. Men work shorter hours and less vigorously in a temperate one. They cannot play hard either. They live easily. They can relax by reading, by sipping cool drinks, or by listening to soothing music. They must try to conserve their energy."

As can be seen from this discourse, the topic sentence is the starting point of the article followed by the specification of facts, and a conclusion in the end. This is a typical structure mirroring linear thought pattern.

\section{Conclusion}

As can be seen through the analysis, thought patterns are deeply rooted in a particular culture, and different culture will have totally different thought patterns. And how we say things is assumed to be determined by some settled thought patterns. Chinese and English are totally different language system. Therefore, it is difficult for a Chinese to learn a language that totally different from them, and vice verse. Chinese English learners tend to apply Chinese thought patterns when learning English, thus contributing a negative influence on English learning. Therefore, to 
overcome the negative influence of the Chinese thought patterns maybe essential for English learning. Firstly, it is necessary to encourage students to learn the culture of English language, especially the thought patterns and regard learning them as an indispensable element of English class. Secondly, the awareness of the influence of Chinese thought patterns on English learning is equally important on the final mastery of English. Thirdly, a comparison study between the thought patterns of the two cultures and a combination of these thought patterns with the teaching of language skills, especially English writing should be adopted in classroom teaching. The study of these differences should be systematically and thoroughly for the familiarity with the differences between the Chinese thought patterns and the English ones and the transference between the two will be an effective way for English learning.

\section{References}

[1] Connor, Ulla. Contrastive Rhetoric [M]. New York: CUP, 1996.

[2] Kaplan, R. Cultural Thought Patterns in intercultural Education [M]. Language Learning. 1966, (2): $15-27$

[3] Parl Pribram. Conflicting Patterns of Thought [M].Washington: Public Affairs Press. 2004

[4] Samovar, Richard E. Porter. Communication Between Cultures [M]. New York: Wordsworth Publishing Company, 1995. 